\title{
In Search of a Link between Planning and Service Delivery: How can we Explicate Service Delivery Gap Using Primary Education and Agricultural Extension Services in Tanzania?
}

\author{
Wilfred U. Lameck \& Denis J. Kamugisha \\ School of Public Administration and Management, Mzumbe University, Tanzania \\ P.O. BOX 2, Mzumbe University, Morogoro \\ Email: wilfredlameck@yahoo.com
}

Doi:10.5296/ jpag.v5i4.8864 URL: http://dx.doi.org/10.5296/ jpag.v5i4. 8864

\begin{abstract}
Planning is a life blood of development. It creates a path through which initiatives can be translated into practice. This is possible if planning is made to be as integrative as possible to guarantee systematic coverage of all crucial aspects for attainment of articulated goals. It delineates key issues over which the tenets of different courses of action should be anchored. All the way through, Tanzania has been striving to adopt and execute an integrative planning process to attain its desired development. From 1960s through 1970s to early 1980s, Tanzania was found to be busy experimenting conventional planning process in all development circles. Nevertheless, conventional planning has been accused of being supply driven rather than demand driven. In reaction to this, from the early $21^{\text {st }}$ century, Tanzania, like other developing countries, officially adopted a bottom up planning approach. Despite that deliberate intervention, the current practice still embraces top down model. This is so because the center still retains decision making powers and its priorities prevail over grassroots priorities. The objective of this article is to explain this failure of planning process which results to service delivery gap. In doing this, we compared the delivery of primary education in Moshi Municipal Council and that of agricultural extension services in Hai District Council.
\end{abstract}

Keywords: Planning, service delivery gap, primary education, agricultural extension services 


\section{Introduction}

It is without shadow of a doubt that pitiable service delivery such as primary education and extension agricultural services is attributed to numerous factors. Some of them are effective planning, resource base and contextual (environmental) elements. This article focuses on planning which is viewed as an impediment to effective and sufficient service delivery.

Anchored on Mintzberg's (1994) conception, planning means a formalized process geared towards producing articulated results in the form of integrated system of decisions. It involves the collection and examination of data; the evaluation of alternative courses of action and the creation of systems for implementation (Stifte, 2000). The planning notion is important because it reduces the cost nuisance and congestion, protection of resources, reduction of taxes or of public costs, provision of a stable business environment, as well as improvement of environmental quality and livability (Weimer \& Vining 1992, Klosterman 1985). While many efforts have been set to ensure effective planning process, the current state of affair demonstrates that the process does not attain the intended outcome because the preferences of the community are undermined (Ndunguru \& Lameck,2011; Babeiya et al. 2014). The key question here is that: why planning has not been an elixir to service delivery throughout history despite of the deliberate efforts the State has been taking to ameliorate the dilemma? While we are cogitating about that, let us first familiarize ourselves with the key concepts.

\section{Conceptualizing the Planning Process}

The planning process has been conceptualized in a number of models. The most common models include: synoptic planning, incremental planning, rational planning and transactive planning. Starting with synoptic planning, this has roughly four classical elements: goal-setting, identification of policy alternatives, evaluation of means against ends, and the implementation of policy. Each stage involves multiple interactions, feedback loops and elaboration of sub-processes. For example, evaluation can consist of procedures such as cost benefit analysis, operations research, systems analysis, and forecasting research. It analyses problems from a systems viewpoint, using conceptual or mathematical models, relating ends to means, with heavy reliance on numbers and quantitative analysis.

Incremental planning argues that policy decisions are better understood, and better arrived at, in terms of the push and tug of established institutions that are adept at getting things done through decentralized bargaining processes best suited to a free market and a democratic political economy. Rational planning model follows ends reduction and elaboration; design of courses of action; comparative evaluation of consequences; choice among alternatives and the implementation of the chosen alternative (Harris \& Britton 1967). A fundamental aspect of this model is the disjuncture between individual rationality and collective rationality. For example, the individuals may know what they want, but cities and regions may not decide based on their best interest. In certain situations, individual preferences aggregated to a societal level produce illogical or undesirable outcomes (Schelling \& Thomas 1971). If the group made a decision as a whole, it would be far different from the sum of the individual decisions of the members. Planners are seldom able to achieve their objective and their 
claims to comprehensiveness if they are not backed up by reality (Altshuler's 1965). The decision-makers often ignore the citizens' wishes in favour of the wishes of politically connected stakeholders.

Transactive planning focuses on the intact experience of people's lives revealing policy issues to be addressed. In this model, the planning is not carried out with respect to an anonymous target community of beneficiaries, but through face-to-face contact with the people affected by decisions. It consists of less field surveys and data analyses, but has more of interpersonal dialogue marked by a process of mutual learning. This reflects the evolution of decentralized planning institutions which help people to take increased control over the social processes that govern their welfare (Friedmann 1973).

In this article, we followed this last model which shows that planning should involve interpersonal learning and mutual dialogue in a decentralized setting. Our argument is that, the manner plans evolve and get executed relates with feasible or unfeasible service delivery in either case, be it agriculture or education. If we take Mintzberg's (1994) conception, for planning procedures to yield anticipated development results, it has to be in the form of integrated system of decisions making. This notion is embedded in transactive planning model. So far, the Tanzanian experience today indicates that integrative planning has been utopian, it has not wholeheartedly influenced sound delivery of essential services. But how can we explicate service delivery gap using primary education and agricultural extension services? We invoke two opposing channels within the planning processes to reveal service delivery gaps. One is conventional approach and the other, bottom up approach. We employ Hai and Moshi cases to justify that unfeasible planning and its embedded intricacies are at the heart of pitiable services delivery.

\section{The Planning Experience in Tanzania}

The first gap with pitiable service delivery starts with the nature of planning processes. In Tanzania, the efforts to ensure sound development started immediately after the withdrawal of the foreign intruders. Three foes to development were clearly identified by the government: namely ignorance, diseases and poverty. Since 1960s the government has been striving to anchor its planning priorities and take initiatives to battle aforesaid development enemies. More than 50 years now, success on such efforts has been on a snail pace. This is justified by the level of poverty transpiring in the entire society today. If we borrow Bolan's (1974) conception, the key role of planning is to 'think about the future'. The fact that the current state of poverty is alarming, justifies that our planning and translation of plans to practice has been problematic. Over 74 percent of Tanzanians who live in rural areas are the mostly affected by ineffective results of planning the state has been trying to resolve (URT 2011a). Most of such people if not all, depend on agriculture. The adopted planning systems and policies (Ujamaa) did not transform agriculture. Hyden (1980) calls this scenario as 'un captured peasantry'. The same scenario is encountered in education system where illiteracy level is burgeoning (Mushi 2009). Hyden and Mushi (ibid), in short justify that planning endeavors have since not been viable. It is high time to agree with Mosha (2006) that, without effective planning and implementation, anticipated level of development cannot be feasible. 
Due to that problem, Tanzania is labelled as the 'low human development' state (UNDP 2013 cited in Babeiya et al. 2014:14), regardless of its endowment in natural resources. The indicators used to arrive at that conclusion engrossed knowledge, standard of living, and a long and health life. Amidst 185 countries, Human Development Index (HDI) ranks Tanzania 152. Deliberately this information shows that, we lost battle against the three development foes: why do ignorance, and diseases and poverty remain high? This predicament automatically is attributed to pitiable planning.

The period from 1960s (Tanganyika independence, Zanzibar revolution, and birth of United Republic of Tanzania), through 1970s to early 1980s, the planning system in Tanzania had been more conventional than something else. Babeiya et al. (2014:15) add that, 'top down approach has predominantly guided the planning and implementation of development initiatives'. The term 'top down approach' in this article is used interchangeably with conventional planning.

Conventional planning is characterized by the center or any organ engulfing grassroots decision making powers. Donors, currently known as Development Partners (DPs) also tend to dictate or influence superimposed decisions to the people. It has been difficult to implement superimposed projects (agricultural and educational) sustainably because beneficiaries see them an unviable. The experience shows that imposed interventions encounter resistances from target populaces. That quest does not increase beneficiary commitment rather than demoralizing the people. This is because the target citizens do not find owning such projects. It is this sense of lack of ownership that leads to elusive commitment. What examples can be drawn to justify aforesaid notion?

We recognize various programs which represent top down approaches, villagization program' in Tanzania stands as a good example. Kamugisha (2011) in his article 'collective action' indicates that Tanzania used the conventional model to inculcate a spirit of collective action, the spirit of working together to fight poverty (ibid, p.2). Nyerere (1968) (father of the nation of Tanzania), on his writing 'freedom and socialism', had a dream that if people work together and stay in communities rather than individualistically, they would advance more, socially and even economically. So, the Ujamaa policy was introduced to bring together people from scattered premises to more defined units where they could be supplied with essential services like education and agriculture.

In line with that, Babeiya et al. (2014), posit that, villagization program that came in 1973, radically aimed at transforming rural livelihoods through the creation of collective social and administrative units known as Ujamaa villages. According to Mhando (2011), such units were thought to be effective instruments for facilitating development administration via socialism and rural development policy with the purpose of improving access to essential social services and scale up agricultural productivity and reinforcing self reliance. Kamugisha (2011), argues that despite this being done with the best of intention, it was in fact a top down policy, with the centre dictating everything. As a result, superimposed projects never became true property of the people; the beneficiary did not accord them with requisite care and eventually the project collapsed. If we use Mushi's (2009:187) observation, we note that: 
By mid-1980 the public primary schools were in a state of collapse. Schools were characterized by collapsing of building, lack of teaching and learning materials, and unmotivated and under-qualified teachers.

Mukandala and Peter (2004: 13) also observed that:

Many schools... [were] desolate in terms of run-down buildings, lack of teaching facilities, such as books, copybooks, chalk, desks, pit latrines, teacher houses and offices, and suffered a serious shortage of classrooms. The government owned primary schools became the least conducive places for learning.

The second planning gap is that, planning has not fostered service delivery ownership. Why? The Tanzanian experience indicates that ownership of development projects particularly those based on agriculture and education, for quit long, have been driven by donors. Donors fund certain projects and sometimes do not release fund in time. Since we anchor our plans on donor funds, this scenario frustrates the planning process. The Tanzania historical development truly shows how over dependence stood as a stumbling block to development especially in the earmarked aspects. Sobhan (2001:90 cited in Babeiya et al. 2014:16) confirms that:

“...while aid financing of development budget fell from 33 to 28 percent between the first half and the second half of the 1960s, it gradually rose to 55 percent between 1980 and 1985 ...from 1986 onwards, aid finance came to exceed total development expenditure in Tanzania, rising from 129 percent in 1986 to 170 percent in 1993-94"

Tripp (2012) indicates that over foreign aid dependence to government budget is slightly going down. This is because while in the financial year (2007/08) dependency on foreign aid was 42 percent, in the financial year (2010/11), dependency slightly dropped to 28 percent. Paradoxically, a comparison between foreign aid against development budget, reveals that "80 percent of the development budget depends on foreign aid assistance" (Tripp, 2012:13). Development budget is what facilitates development of agriculture and education, among others. This implies that, should external quandaries affect development Partners (DPs), recipient countries with its populaces suffer the consequences. There will be little money allocated for either education or agriculture as a result of imbalances in global economic dynamics or something else that may influence DPs to discredit their commitment to recipient budget. The fact that the country is not liquid enough to support earmarked aspects from taxes and other avenues, ultimately service delivery suffers. For instance, agriculture is one of the sectors that have received less attention from DPs. Although it is the main source of income and that it covers over 70 percent of Tanzanian employment, it contribution to the economy remains 4 percent (Babeiya et al. 2014). The government reports show that, its contribution has been going down year after year.

The speech by the minister of state confirmed that, the agricultural sector contribution to economy declined from 4.2 percent in 2010 to 3.6 percent in 2011 (URT, 2011a). The same was noted on Gross Domestic Product (GDP). GDP dropped from 30 percent in 2000 to 25 percent in 2009. This trend continued from 24.1 percent in 2010 to 23.7 percent in 2011 (ibid). 
Anchored on projections normally set by economist, for agricultural sector to have significant impact in the reduction of poverty, its growth rate must go beyond 5.6 percent. To come to this threshold is like a nightmare due to the current state of incapacity in technical services, lack of modern infrastructure particularly to the lower echelon, limited investment in research and development (R\&D) for agriculture, and limited capital and access to financial services.

Over dependency is also a major factor to poor funding for development of primary education in Tanzania. This is depends on government's commitment to ensure quality education, a dream which for quit long has been seen as an illusion. For instance, the government committed itself to confer 100 percent of capitation grants of \$10 USD per enrolled pupils. It set \$4 USD equivalent to 40 percent for purchase of textbooks, teaching and learning materials and \$6 USD 60 percent for development (URT 2012b). The latter was put under the management of school committees, where 20 percent (\$2) was for repair; 20 percent (\$2)for administration materials (stationery); 10 percent (\$1) for school based examinations, and another 10 percent $(\$ 1)$ for purchase of chalks, pencils and pens (Mbelle 2008:16).

Despite that fact, the government has not been able to fulfil its promises. The major problem is that donor funds are limited, it is imperative to note that, the basis of such plans was attributed to donor interventions. Nevertheless, a number of scholars such Mbelle (2008), indicate that the design of capitation grant $(\mathrm{CG})$ foregone the reality. They posit that $\mathrm{CG}$ is centred on the number of pupils admitted at that school. Consequently, using the number of pupils as basis for allocation of CG is problematic for it does not reflect real school demands. Mbelle (2008) criticises the manner CG is designed and executed. He (ibid, p. 2) argues that CG "operates in the principal of level of inputs determining the level of funding rather than level of demand determining level of funding, which in turn should determine the inputs". Due to this effect, schools go without aforesaid aspects at their requisite panorama

The third planning gap is informed by lack of good governance. The latter became a catchword in development circles in 1990s. It fostered bottom up planning approaches for states to yield the fruits of good governanace. This concept is imperative for development of communities because it puts forward a set of principles necessary to realize social economic development (Mwakasungula et al. 2014:4). This notion is also recognized by article 146 of the Tanzanian constitution (1977) and the ongoing on planning strategy known as O\&OD (URT 2002). Both emphasise on the transfer of authority from the centre to the beneficiaries. Its purpose is to make beneficiaries active players in the planning process and execution of the plans. However, the current state does not reveal this notion clearly. There has been less regard to target beneficiaries in planning processes. Citizens are taken as passive actors who are expected to take whatever course of action decision makers make. The tendency of neglecting beneficiaries voices is happening in neo-liberalism era where there is much encouragement, I, inclusiveness, openness, and transparency in policy making and execution (Babeiya et al. 2014).

Lack of these attributes justifies existence of weak governance framework. Ringold et al. (2012) and Ahmad et al. (2005) indicate that, the Tanzanian governance framework is loose. 
This explains why citizens' involvement in planning processes and respecting of their preferences or priorities has become illusive. The system does not provide avenues for them to demand accountability either directly or indirectly. As a result citizens to a certain extent have lost confidence to the current planning strategy. Mollel (2010) and Massoi \& Norman (2009) in one way or another indicate that, where platforms for citizens to air out their voices are organized, a fraction of citizens do attend or participate. This implies that decisions are made by a few. Paradoxically, even the voices raised by the minority of the lower level beneficiaries find no room in council plans. This justfies Kikula et al's (1999) findings. They found that, council planning processes in Tanzania are not comprehensive. Some people preferences like agriculture and education were not integrated in council plans. This is the same scenario encountered even today. In that regard, we agree with Liviga (2011) who argues that, local governments implement the directives in the form of guidelines, circulars, and policies echoed by the centre, instead of respecting the voices emerging from below.

The fourth gap in the planning approach is that it is anchored on the role of inter sectoral interactions. This has been a bottleneck to sound service delivery. During the 1961-85 period, there was a move to link agriculture and industrial sector and to link the provision of education with other sectors like ICT and energy sector. The purpose was based on reducing bureaucracy but also focusing on delivering quality education and increasing agricultural productivity. Basing on agriculture, the emphasis was benched on processing agricultural produces. This notion inculcated the industrial sector to produce modern labour or argricultural implements. For instance, a number of industries were introduced like Ubungo Farm Implement (UFI) and Zana za Kilimo (ZZK) Mbeya (Babeiya 2011). However, such initiatives were short lived due to poor performance of state owned enterprises to foster inter-sectoral cooperation in planning processes. We also experienced poor interdependence between the agricultural and education sectors and the energy sector. While ICT is viewed as imperative in education programs like The Primary Education Development Plan PEDP, as a modern way of ensuring learning, and accessing materials, many rural schools are not connected to the national grid. It becomes a paradox to promote ICT in a scenario where there is no electricity. The problem of limited access to electricity remains ubiquitous to date as less than 20 percent of more than 44 million Tanzanians have access to electricity (Babeiya et al . 2014).

The fifth gap is the planning oversight. This has been found in both conventional and bottom up approaches. The key problem here is that, planning is represented by short-sightedness. This is because national planners confine national planning into a narrow and short-term based orientation. Any intervention for improving the state of art is 'narrowly conceived in time and social space' (Babeiya et al. 2014:20). If we take the agricultural sector, we find that Tanzania has been exerting much efforts in promoting more cash crops for export than food crops, instead of promoting both. However, this is not an accident; this problem was triggered by the colonial regimes. According to URT (2011a) reports, for more than five decade Tanzania has relied much on exporting cash crops. We reveal the exportation percentage of certain cash crops here. For instance, coffee contributed 2.8 percent of Tanzania exports, cotton 1.2 percent, cloves 1.6 percent, and tea 0.9 percent. Other items included and 
their contributions are; mineral 44.8 percent re-exports 1.9 percent, unrecorded trade 13 percent, fish and fish products 2.7 percent, horticulture products 0.7 percent, and others 6.8 percent. But very little was done for in exportation of food crops. The experience also indicates that the exportation of food crops even within East African Region has always been taken as illegal.

The same planning oversight is encountered in education. Education programs like PEDP 2001, and Education policies (URT 1995, 2014), have highlighted issues to be accorded weight in offering quality education. One aspects of focus was to make education free. A survey made by Hoogeveen and Rossi (2011) indicates that, primary education in Tanzania has never been free because transaction costs have superseded the tuition fee. Transaction costs include fees on transport, exercise books, uniforms, meals and other contributions (desks, examinations, etc). Therefore, 'free' meant only tuition fee. We argue that, this is in fact a total oversight. For that matter planning has not increased the desired resources like fiscal, physical and human resources. These are the major predicaments encountered in the provision of education in Tanzania. The government reports show that, it has been difficult to ensure 100 percent capitation grants to schools. The Ministry of Finance has been transferring less or around to 50 percent capitation grants (CG) to local governments (URT 2010a). The URT (2012a) report shows that CG transferred to local governments accounted for 31 percent in 2007, 54 percent in 2008, 67 perecnt in 2009, 54 percent in 2010, 28 percent in 2011, and 22 percent in 2012. Despite the challenges imposed on the design of capitation grants, the garants earmarked have not been reaching schools in the amount required. Despite this oversight in planning, we also encounter another problem of incapacity to ensure direct accountability. One of the intervention of PEDP (URT 2001), was to build the capacity of school committee members to manage the delivery of primary education at the village or neighbourhood level. The study by Massue (2010) found that schools committee members most of them are not conversant with the requisite guidelines and thus are encountered in a paradox of not knowing what do as regards to their roles. This is what explains why their roles are not very much feasible. Despite the empirical literature on the predicament of the planning process, there is little which has been done to alter the tradition of top down planning. This raises a question on why the planning process increases service gap despite all this initiative.

\section{The methodology}

This article is informed by a qualitative research with comparative case study design which was conducted in Hai and Moshi municipal council. In answering the question on how the planning process takes place and and why it fall short, the case study design was sought appropriate. The interviews and focus group discussion with council officials, school teachers, politicians and citizens involved in the planning process were used to unvail the complex of factors which obstruct the planning process. To this end, the actual planning process in the two cases was reconstructed and finally a comparative analysis was conducted to provide more rigour insights on the actual planning in the two cases 


\section{The Case of Planning Process for Agriculture in Hai District Council}

In Hai district, the planning for agricultural extension services is guided by five years strategic plans and annual district agricultural development plans. The strategic plan is a general five year plan that formulates goals for all policy sectors including agriculture and livestock. The development of the strategic plan for the period of 2011/2012 - 2015/2016 was almost entirely in the hands of the heads of departments of the council. Procedures prescribe that, stakeholders must be consulted in the process of drawing up the plan, but with regard to agriculture and livestock stakeholders such as farmers' groups, farmers' organizations or cooperatives were not asked to provide input. It was only in the last phase of the preparation of the plan when some stakeholders like community and traditional leaders were consulted (Hai district strategic plan 2011:3-4). With respect to agriculture, some general issues were identified as threats or challenges such as climate change and the low adoption rate of modern methods for agriculture and livestock keeping. There is no doubt about the fact that central government policies and priorities were important guidelines for the formulation of strategic objectives. .

With respect to annual plan, the council must also develop annual plans for each sector, including agriculture. The process has to begin at the lowest level -the village level and must be guided by formal planning methods known as Obstacles and Opportunities to Development (O \& OD). The use of this method is supposed to be facilitated by district and ward officials who form facilitation teams (DADPs Project 2012).

In practice, the planning for agricultural development begins at the village level. Every year, the district executive director issues a letter to instruct the village chairperson to organize a special village assembly (Interview DAEO). The assembly is attended by district and ward extension officials, who are members of their respective facilitations teams. Although the district has approximately 49600 number of farmers who are supposed to suggest their priorities, the extension officials lead them by explaining the problems and opportunities associated with their choice. If the extension officials think that the project proposed by farmers cannot work or if it is inconsistent with government priorities, they change it (interviews DAEO, DALDO, Rundugai WAEO and VAEO).

Strict selection of projects conforming to central government priorities is even more necessary now that the grants for agricultural development programs are phasing out and that there is little fund available to be allocated to projects. As a consequence, the district has been ordered by central government to identify only two priorities, one for crop production and one for livestock.

\section{The Case of Planning Process for Education in Moshi Municipal Council}

The current planning process for development of education in Moshi Municipal Council is guided by the 1995 and 2014 education policies. Its objective is to ensure growth and equitable access to high quality formal education and adult literacy. This would be attained through facilities expansion, efficiency gains and quality improvement, in line with efficient supply and use of resources. It is also guided by the Basic Education Master Plan (BEMP) 
which was developed by the government in 1997 to guide the development in basic education provision. Besides, it is guided by O\&OD, the current strategy which calls for villagers or neighborhoods engagement in education planning process and execution of citizen's priorities. It is as well guided by the Primary Education Development Programs (PEDP). Phase one for instance intended to: improve education quality, expanding school access, and increasing school completion at the primary level; increase resource availability and improve resource allocation and utilization; improve educational inputs; and strengthen institutional arrangements for effective primary education delivery, particularly by empowering grassroots stakeholders (URT 2001).

However, the current strategic plan in promoting education takes care of the aspects raised in education policies, BEMP, O\&OD, and PEDP. The current state shows that still there are a number of problems related with planning approaches to attain quality education. This part gives an account of three aspects to justify that contention: namely free education as emphasized in education policies, participation of citizens in managing education, 100 percent flow of capitation grants to primary schools.

Anchored on free education, the experience shows that, although the government is committed to ensure free education as an imperative aspect in planning strategy to enable every parent take his/her child to schools, parents in Moshi have always been required to contribute. The major impediment has been on transaction costs. This covers transport fee, meals, uniforms, exercise books and other contributions like desks, and exams fees. For low income earners, it has been a burden to afford basic education costs (interviews by parents and village leaders).

The picture in Moshi also reveals that, there is ineffective participation of beneficiaries in the process of planning to ensure the delivery of quality education. Although the District acknowledges that, it involves citizens in planning processes particularly in education matters as required by O\&OD, the picture on the ground is different. During participatory meetings carried out to collect educational issues, a few citizens do attend such meetings. This happens because citizens do not have confidence with their authorities to respect their (citizens) views. So, they find attending such meetings is like wasting time. As a result, few beneficiaries make decisions on behalf of the majority. This implies that, such plans are to some extent not legitimate. Eventually, for those priorities tabled by minority when reach decision making organs are not respected. This is justified by the fact that, no feedback is given to interviews with village leaders, parents, ward education officers, municipal planning officers, and municipal community development officers). The municipal officials claim that, all development plans require a thorough budget. They attribute such problems to limited fiscal resources. This justifies that, the municipality lacks enough fiscal resources to undertake its obligations. This also explicates the reason why the priorities raised by the community go without being accorded requisite weight. Lack of resources to local governments is also justified by the Ministry of Finance (MoF) acknowledging that it allocates below 50 percent of capitation grants to local government for schools development. This is a major quandary that encumbers sound bottom up approach and as a result limits service delivery. 
The third experience as shown earlier is that, the flow of capitation grants to primary schools is problematic. Although that has been raised above, two primary schools (Kiboriloni and Njoro) have been earmarked to show the trend of flow of capitation grants. Table 1 gives a clear picture.

Table 1: Actual Devolved Capitation Grants in Njoro and Kiboriloni Primary Schools

\begin{tabular}{|l|l|l|l|l|}
\hline & Kiboriloni $(4 \$+6 \$)$ & Deficit & Received & Deficit \\
\hline & Received & $2,881,200$ & 786,160 & $5,553,840$ \\
\hline$(\%)$ & $3,978,800$ & 42 & 12.4 & 87.6 \\
\hline 2012 & 419,300 & $5,570,700$ & $3,233,400$ & $3,106,600$ \\
\hline$\%$ & 7 & 93 & 51 & 49 \\
\hline 2011 & 800,280 & $4,139,720$ & 832,000 & $5,568,000$ \\
\hline$\%$ & 16.2 & 83.8 & 13 & 87 \\
\hline 2010 & 693,620 & $3,696,380$ & $1,116,280$ & $5,373,720$ \\
\hline$\%$ & 15.8 & 84.2 & 17.2 & 82.8 \\
\hline
\end{tabular}

Source: Field data (2014)

The findings in Table 1 show the trend of capitation grants devolved to selected schools and its deficit in percentage per year as follows: The capitation grants devolved to Mnazi primary school (Kiboriloni) was 58 percent in 2013, 7 percent in 2012, 16 percent in 2011 and 16 percent in 2010. For Njoro, it was 12 percent in 2013, 51 percent in 2012, 13 percent in 2011 and 17 percent in 2010. The deficit of capitation grants for Mnazi primary school (Kiboriloni) was 42 percent in 2013, 93 percent in 2012, 84 percent in 2011 and 84 percent in 2010. For Njoro, the deficit was 88 percent in 2013, 49 percent in 2012, 87 percent in 2011 and 83 percent in 2010. The above findings show that the governments cascades little money to schools. In that regard, schools cannot offer requisite education.

Despite this bottleneck, the required amount is not benched on the level of inflation. Currently, the government uses 1 dollar per TZS 1,000 while the current exchange rate is almost 1 dollar per TZS 2200. The former is not realistic: government plans are technically unfeasible. 


\section{Macrothink \\ Journal of Public Administration and Governance \\ ISSN 2161-7104 \\ 2015, Vol. 5, No. 4}

\section{The comparative Analysis of Planning Gap between the Two Cases}

Comparatively, the two councils are disposed of the same form of administrative system. They all function under the decentralisation by devolution system which was introduced as a vehicle for reforms in the two councils. The new planning model was introduced in the two councils which involve the use of O\&OD methodology to plan for effective and sufficient services. This is supported by the government which issues the guidelines for planning in both policy sectors. Unlike education sector where the grants flow in form of capitation grants direct to schools and managed by schools committees members, in agricultural sector, the grants flow in form of capacity building, extension block and agricultral development grant to local government authorities and it is managed by head of department of agricultre under the supervision of a district executive director. Similarly, in both councils, the grants transferred to local government by central government are earmarked for specific activities. If the citizens plan for the services, they must conform with central government priorities identified. This implies that although the planning process is supposed to precede bottom up, the central government priorities influence the content of plans at the local level. Hence, instead of government seeking for grassroots' priorities, citizens' priorities must conform to central government priorities.

\section{Explanation and Conclusion}

Our central question of this article was to explore how the planning process in Tanzania takes place and why the process end up with the disappointing results? Our empirical data shows that in both councils the content of the plans and programs is influenced by central government priorities and guidelines, contrary to the intent of the reform paper. If the farmers for instance, suggest a project which is against central goverment priorities, it is likely that the officials at the district level would not accept such a plan. This is similar to education sector where the capitation grants is directly designed and allocated by central government. Apart from the formal arrangement, the informal social rules also play a role. If the officials make decisons, they must look up to their bosses at the ministry. This is because the centre hires local government officials, pay their salaries and promote them. Although local government officials are formally supposed to listen to claims of citizens, they do not often do so because, at the same time, they have to satisfy their superiors at the central government level.This notion of dual accountability explains why service delivery falls short in Hai District and Moshi Municipal Councils. 


\section{Macrothink}

\section{Reference}

Ahmad, J., Devarajan, S., Khemani, S. and Shah, S. (2005). Decentralization and Service Delivery. World Bank Policy Research, Working Paper 3603. The World Bank.

Babeiya, E., Mateng'e, F., Kihamba, J., (2014). National Planning and the Quest of Transforming Rural Livelihood in Tanzania. Journal of Education Humanities and Sciences 3,(1\&2), pp.13-26

Altshuler, A (1965) The City Planning Process. Cornell University Press.

Babeiya, E. (2011).Liberalization and Public Policy Making in Tanzania: A cross Sector Experience. Elixir Soc.Sci.40:5608-5617.

Friedmann, J (1987) "The Social Mobilization Tradition of Planning",in Planning in the Public Domain: From Knowledge to Action. Princeton University Press.

Harris,B (1967) The Limits of Science and Humanism in Planning. Journal of the American Institute of Planners. 33 (??):324-335.

Hyden ,G (1980). Beyond Ujamaa in Tanzania: Underdeveloped and Uncaptured Peasantry. Berkeley: University of California Press.

Kamugisha, D. (2011). Collective Action. In: J. Itika, K. de Ridder \& A.Tollenaar, eds., Theories and Stories in African Public Administration, pp. 11-24. Leiden: African Studies Centre.

Mbelle, A.V.Y. (2008). The Impact of Reforms on the Quality of Primary Education in Tanzania. Research Report No.08.1, Dar es Salaam: REPOA.

Mhando, L (2011). Tanzania and the Geo-politics of Rural Development: in Return of Neo Liberalism. Journal of Emerging Knowledge on Emerging Markets, 3 (??): 455-4772

Mintzberg, H. (1994). The Rise and Fall of Strategic Planning .New York: The Free Press Mosha, H (2006). Planning Education Systems for Excellence. E\&D limited, Dar es Salaam.

Mushi, P.A.K .(2009). History and Development of Education in Tanzania. Dar es Salaam: Dar es Salaam University Press..

Nyerere, J.K (1968). Freedom and Socialism. Dar es Salaam: Oxford University Press

Ndunguru, J.M. \& Lameck W.U. (2011) Community Participation. In: J. Itika, K. de Ridder \& A.Tollenaar, eds., Theories and Stories in African Public Administration, pp. 11-24. Leiden: African Studies Centre.

Schelling, T. (1971) "On the Ecology of Micromotives” The Public Interest. 25 (??):61-98.

Sobhan, R.(2001). Aid Dependency and Policy Ownership .The Tanzanian experience with Lessons from Bangladesh. Identity, Culture and Politics, 2 (1): 85-114 


\section{Macrothink}

Journal of Public Administration and Governance ISSN 2161-7104

Tripp, A.M. (2012). Donor Assistance and Political Reform in Tanzania. Working Paper No.2012/37United Nations University, World Institute for Development Economics Research

URT.(2011a). Speech by the Minister of State, President's Office, Social Relations and Coordination Hon. Stephen M. Wasira (MP), Presenting the State of the Economy for 2011 and National Development Plan for 2012/13 to the Parliament. Dodoma.

URT. (2011b). Poverty and Development Report 2011. Dar es Salaam: Government Printers.

URT.(2011c).The Economic Survey 2011.President's Office, Planning Comission.

Kikula, I., Barry Dalal-Clayton., Christopher, C and Hilda, K. (1999). A Survey of Some Current Approaches to Participatory Planning at District Level, Volume I, MRALG/UNDP. Dar es Salaam, July 1999.

Massoi, L and Norman, A. S. (2009). Decentralization by Devolution in Tanzania: Reflections on Community Involvement in the Planning Process in Kizota Ward in Dodoma. Journal of Public Administration and Policy Research 1(7), pp. 133-140.

Masue, O. S. (2010) Empowerment and Effectiveness of School Committees in Tanzania. Bergen, University of Bergen.

Mollel, H.A. (2010). Participation for Local Development: The Reality of Decentralization in Tanzania. Leiden: African Studies Centre.

Mukandala, R.S and Peter, C.M. (2004). Local Government, Effectiveness and Human Rights. Geneva: International Council on Human Right Policy.

Ringold, D., Holla, A., Koziol, M and Srinivasan S. (2012).Citizens and Service Delivery: Assessing the Use of Social Accountability Approaches in Human Development. Washington DC: World Bank.

Stifte, B (2000) The planning Theory, the National AICP Examination Preparation Course Guide book, 6-16 publisher

URT. (2001). ESDP: Primary Education Development Plan (PEDP1) 2002-2006. Dar es Salaam: Basic Education Development Committee (BEDC)

URT. (2010a). Education Sector Performance Report 2009/10. Dar es Salaam: Education Sector Development Committee, September 2010.

Weimer, D.L. \& Vining, A.R. (1992) Policy Analysis: Concepts and Practice, $2^{\text {nd }}$ edition. Prentice-Hall. 